\title{
Triagem das hemoglobinas S e C e a influência das condições sociais na sua distribuição: um estudo em quatro comunidades quilombolas do Estado do Tocantins'
}

Screening of hemoglobins S and C and the influence of social conditions in their distribution: a study in four quilombola communities, Tocantins state

\author{
Lidiane Oliveira de Souza \\ Graduada em Ciências Biológicas. \\ Endereço: Avenida Goiás, 469, Setor Jardim Querido, CEP 77500- \\ ooo, Porto Nacional, TO, Brasil. \\ E-mail: lidianeoliveiradesouzaœyahoo.com.br \\ Annyelle Figueredo Teles \\ Graduada em Ciências Biológicas. \\ Endereço: Rua Cruzeiro do Sul, 217, Setor São Judas Tadeu, CEP \\ 77500-000, Porto Nacional, TO, Brasil. \\ E-mail: annyelletelesळyahoo.com.br

\section{Rafael José de Oliveira} \\ Mestre em Engenharia Agronômica. Professor Assistente IV - Uni- \\ versidade Federal do Tocantins (UFT). \\ Endereço: Rua 22, 869, Setor Aeroporto, CEP 77500-000, Porto \\ Nacional, TO, Brasil. \\ E-mail: rafaelळuft.edu.br

\section{Maria Aparecida de Oliveira Lopes} \\ Doutora em História. Professora Adjunta - Universidade Federal \\ do Tocantins (UFT). \\ Endereço: Alameda 14, Lote 16, 504 Sul, CEP 77021-68I, Palmas, \\ TO, Brasil. \\ E-mail: maparecidalopesळbol.com.br

\section{Ibis Alan de Souza} \\ Graduado em História. \\ Endereço: Rua Donato Santana, 235, Setor Cruzeiro do Sul, CEP \\ 77500-000, Porto Nacional - TO, Brasil. \\ E-mail: ibisalanæhotmail.com
}

\author{
Vélma de Souza Santos Inácio \\ Técnica de Laboratório (Patologia Clínica). Diretora de Relações \\ Públicas. Associação dos Falcêmicos do Estado do Tocantins \\ (Afeto). \\ Endereço: Alameda 29, Lotes 72/74, 307 Norte, CEP 77001-436, \\ Palmas, TO, Brasil. \\ E-mail: velmasouza®hotmail.com \\ Carla Simone Seibert \\ Doutora em Fisiologia Geral. Professora Adjunta - Universidade \\ Federal do Tocantins (UFT). \\ Endereço: Rua 03, lote 17, S/N, Jardim dos Ipês, CEP 77500-000, \\ Porto Nacional, TO, Brasil. \\ E-mail: carlaseibertळyahoo.com \\ Apoio Financeiro: Secretaria de Ciência e Tecnologia do Estado \\ do Tocantins - SECT, convênio PPSUS n 700.612/08.
}




\section{Resumo}

Neste trabalho foi realizada a triagem das hemoglobinas S e C e o estudo do perfil social de quatro comunidades quilombolas. $\mathrm{O}$ estudo foi desenvolvido nas comunidades quilombolas de Malhadinha, Córrego Fundo, Curralinho do Pontal e Manoel João, município de Brejinho de Nazaré (TO). O perfil das hemoglobinas foi obtido com a triagem de 167 amostras de sangue, utilizando o teste de eletroforese em pH alcalino (pH 8,6). Para confirmar o diagnóstico, as amostras alteradas foram submetidas à eletroforese em $\mathrm{pH}$ ácido (pH 6,2). Foram identificadas 11 amostras $(6,6 \%)$ com hemoglobinas variantes: oito $(4,8 \%)$ com traço falciforme e três com hemoglobina C (1,8\%). Os dados sociais foram obtidos através de entrevista realizada com representantes de 48 famílias, levantando informações sobre a renda familiar, idade, sexo e atividade ocupacional de cada indivíduo. 0 estudo mostrou que essas comunidades são formadas predominantemente por adultos e idosos, com renda mensal maior que um salário mínimo, para 50\% das famílias entrevistadas. Apesar do percentual das hemoglobinas S e C encontradas nas comunidades estarem dentro do observado para várias regiões do Brasil, a ausência de informação sobre a doença e os aspectos sociais podem aumentar o número de indivíduos com doença falciforme no município ou áreas vizinhas.

Palavras-chave: Hemoglobina; Traço falciforme; Comunidades quilombolas; Perfil social.

\section{Abstract}

This research performed the screening of S and C hemoglobins and a social profile study of four Quilombola communities. The study was performed at the communities of Malhadinha, Córrego Fundo, Curralinho do Pontal and Manoel João Quilombola, located in the Brejinho de Nazaré municipality, Tocantins state, Brazil. The hemoglobin profile was obtained by screening on 167 blood samples using the electrophoresis in alkaline $\mathrm{pH}(\mathrm{pH}$ 8.6) test. Chemically altered hemoglobin was subject to electrophoresis in acid $\mathrm{pH}$ ( $\mathrm{pH}$ 6.2) to confirm the diagnosis. We identified 11 samples (6.6\%) with hemoglobin changes, eight (4.8\%) had sickle cell trait and three were $\mathrm{C}$ hemoglobin (1.8\%). Social data was obtained by interviews conducted with members of 48 families, raising information such as family income, age, gender and occupational activity. Our results showed that these communities are formed predominantly by adults and elderly people with monthly revenue higher than the minimum wage, accounting for $50 \%$ of the interviewed families. Although the percentage of hemoglobin S and C found in all the communities are within the values observed within the various regions of Brazil, the absence of information about the disease and social aspects may increase the number of people with sickle cell disease in the municipality and surrounding areas. Keywords: Hemoglobin; Sickle Cell Trait; Quilombo Communities; Social Profile. 


\section{Introdução}

As hemoglobinas (Hb) S e C são variantes da $\mathrm{Hb}$ A, que resultou de uma desordem genética causada pela alteração de um único par de bases, desencadeando a síntese anormal das cadeias globínicas. Naquelas duas hemoglobinas variantes, a alteração aconteceu no sexto aminoácido, sendo o ácido aspártico substituído por uma valina na $\mathrm{Hb} \mathrm{S}$ ou, por uma lisina na $\mathrm{Hb} \mathrm{C}$.

Os indivíduos que apresentam eritrócitos cujo conteúdo predominante é a Hb S possuem a anemia falciforme (expressa pelo genótipo SS). Em condições de hipóxia, desidratação ou estresse fisiológico, os eritrócitos do indivíduo com esta anemia sofrem alterações morfológicas, adquirindo forma de foice. Os eritrócitos nestas condições não circulam adequadamente na microcirculação, desencadeando hemólise e obstrução do fluxo sanguíneo capilar, o que estabelece a grande maioria dos sinais e sintomas presentes nas manifestações clínicas dos pacientes. A hemoglobina S pode se associar com outras hemoglobinopatias como a $\mathrm{Hb} \mathrm{C}$ ou talassemias, sendo os sintomas clínicos semelhantes ao da anemia falciforme (Ballas e Mohandas, 1996; Di Nuzzo e Fonseca, 2004). Assim como a $\mathrm{Hb} \mathrm{S}$, a Hb C também é uma hemoglobina de agregação, em homozigose (Hb CC) forma cristais intraeritrocitários, mas em menor frequência e intensidade (Bonini-Domingos, 2009).

Os indivíduos heterozigotos para a $\mathrm{Hb} \mathrm{S}$ herdam somente um gene alterado de um dos seus genitores, o que é denominado traço falciforme (Hb AS). Estes não apresentam as manifestações vasoclusivas observadas no indivíduo com anemia, no entanto, há alguns relatos que associam a morte e complicações clínicas às condições que propiciam o processo de falcização dos eritrócitos, especialmente quando expostos às situações extremas de baixa tensão de oxigênio $\left(\mathrm{O}_{2}\right)$, acidose e desidratação (Harkness, 1989; Murao e Ferraz, 2007; Pinto e col., 2008). Cabe destacar que os indivíduos com traço falciforme são assintomáticos e tal situação não interfere na sua expectativa de vida (Murao e Ferraz, 2007), o que também é observado nos indivíduos heterozigotos para a hemoglobina C (Bonini-Domingos e col., 2003).
Em várias regiões da África² e outras partes do mundo onde a malária (ocasionada pelo Plasmoldium falciparum) é endêmica, ser portador da $\mathrm{Hb}$ S tem um significado adaptativo importante, visto que indivíduos nessas condições apresentam maior resistência à infecção pelo parasita, o que representa maior proteção contra a doença (Brasil, 2007). Joishy e colaboradores (1988) afirmam que a frequência de malária causada pelo P. falciparum na Índia é menor em indivíduos $\mathrm{Hb}$ AS do que em indivíduos normais (Hb AA). Outros estudos mostraram grande associação entre a resistência clínica à malária em heterozigotos e hemozigotos da $\mathrm{Hb} \mathrm{C}$ (Modiano e col., 2001) e que portadores de $\mathrm{Hb}$ AS e Hb AC podem limitar a expansão de infecção causada pelo Plasmodium (Pascal e col., 2004; Kreuels e col., 2010).

Nas populações expostas à malária, aconteceram várias mutações da hemoglobina S (haplótipos de Hb S). Quatro das mutações ocorreram na África e receberam os nomes das respectivas regiões conforme origem geográfica: Senegal, Camarões, Benin e Bantu. Já a mutação, denominada tipo Árabe-Indiano, como o nome indica, originou-se na Ásia Menor e Índia (Gonçalves e col., 2003). 0 comércio de escravos para o Brasil envolveu africanos de várias partes do continente, entretanto, as regiões que compreendem Angola, Congo, e Moçambique tiveram papel majoritário (povos genericamente definidos como Bantu). Estudos moleculares dos haplótipos de $\mathrm{Hb}$ S em diferentes regiões do Brasil identificaram o haplótipo Bantu como o mais prevalente na população brasileira (Vicentino e Dorigo, 2002; Galiza-Neto e col., 2005; Bezerra e col., 2007). 0 indivíduo com anemia falciforme de origem Bantu apresenta baixa concentração de hemoglobina fetal, fator que torna a manifestação clínica mais agressiva (Rieder e col., 1991; Zago e col., 1992).

No Brasil, a prevalência de heterozigotos para a $\mathrm{Hb} \mathrm{S}$ entre os afrodescendentes é maior nas regiões Norte e Nordeste, acometendo de 6\% a 10\% da população, enquanto nas regiões Sul e Sudeste essa prevalência é menor ( $2 \%$ a $3 \%$ ) (Cançado e Jesus, 2007). Neste contexto, encontra-se o Estado do Tocantins, no qual a influência negra é evidente. Segundo dados do IBGE (2011), aproximadamente $72 \%$ da população

2 Como a República do Benim e a região etnologística denominada de Bantu. 
que habita as diversas áreas urbanas e rurais do Estado se declaram negras ou pardas. Nessa região existem várias comunidades quilombolas, que durante muitos anos se mantiveram totalmente isoladas, sem assistência de órgãos públicos e demais instituições sociais (Nascimento, 2009). Somente a partir da promulgação da constituição brasileira de 1988 foram iniciadas as discussões acerca do reconhecimento das comunidades quilombolas pela Fundação Cultural Palmares. Até o momento, há 29 comunidades quilombolas no Estado do Tocantins, 27 já reconhecidas e 2 em processo de reconhecimento (Fundação Cultural Palmares, 2013).

Segundo Fiabani (2011), algumas das comunidades quilombolas se formaram a partir de antigos quilombos, outras se originaram após a Abolição, com a ocupação de terras devolutas. Em relação à distribuição dessas comunidades, quase todas estão localizadas em municípios da bacia do rio Tocantins, sendo que apenas duas (Cocalinho e Bavieira) situam-se na bacia do rio Araguaia (Nascimento, 2009).

Como muitos estudos de diagnóstico da doença falciforme, no Brasil, foram realizados com amostras oriundas da miscigenação racial, despertou-se o interesse em pesquisar a população descendente de quilombolas, no Estado do Tocantins. Entre as comunidades reconhecidas no Estado encontram-se a Malhadinha, Córrego Fundo, Curralinho do Pontal e Manoel João, todas localizadas no município de Brejinho de Nazaré (TO). Desse modo, o objetivo do presente estudo foi realizar a triagem das hemoglobinas S e C nas comunidades acima citadas e avaliar sua estrutura social, uma vez que esta pode ser um fator determinante para o aumento de indivíduos com hemoglobinas de agregação.

\section{Metodologia}

\section{Área de estudo}

A pesquisa foi realizada nas comunidades quilombolas de Malhadinha, Córrego Fundo, Curralinho do Pontal e Manoel João, localizadas na área rural do Município de Brejinho de Nazaré, região central do Estado do Tocantins. Em cada comunidade foram selecionadas cerca de 12 famílias para participarem do estudo. A inclusão das famílias no estudo foi aleatória. As visitas foram realizadas intercalando-se as residências e essa situação foi alterada quando o morador não se encontrava ou não tinha interesse em participar do estudo, partindo-se então para a residência seguinte. 0 representante da família foi esclarecido sobre o trabalho e as atividades foram iniciadas somente após avaliar seu interesse em participar do estudo e consentimento.

Segundo dados disponibilizados pelos representantes, no momento da visita, as comunidades de Malhadinha, Córrego Fundo, Curralinho do Pontal e Manoel João são compostas por 6o, 30, 20 e 30 famílias, respectivamente. 0 quantitativo populacional da comunidade sofre alteração sazonal entre a cidade e o campo, principalmente no período das atividades escolares. A coleta de dados foi realizada nos meses de junho e julho de 2011.

\section{Identificação das hemoglobinas S e C}

Os indivíduos foram informados sobre o projeto, conforme orientação do Comitê de Ética em Pesquisa com Seres Humanos e, após autorização por escrito, foi coletado $3 \mathrm{~mL}$ de sangue venoso, utilizando como anticoagulante ácido etilenodiamino tetracético (EDTA, 10\%), de todos os indivíduos da residência em estudo. As amostras foram triadas com o teste de eletroforese em $\mathrm{pH}$ alcalino (pH 8,6). Para confirmar o diagnóstico, os indivíduos que apresentaram hemoglobinas variantes foram submetidos à eletroforese em pH ácido (pH 6,2) (Bonini-Domingos, 2006).

\section{Perfil socioeconômico}

Para obter os dados socioeconômicos, foi realizado estudo mediante entrevista com o indivíduo responsável pela família (residência selecionada), ao mesmo tempo em que foi realizada a coleta de material biológico (sangue). Todas as entrevistas foram realizadas pelos mesmos auxiliares de pesquisa, previamente treinados. $\mathrm{O}$ anonimato foi severamente seguido.

O guia de entrevista abordou a renda familiar, o número de moradores na residência e os dados pessoais de cada indivíduo da família como sexo, idade e atividade ocupacional. Na análise dos dados, a renda familiar foi classificada por famílias que possuíam renda mensal menor, maior ou igual a um salário mínimo e em relação à idade, os indivíduos foram classificados por faixas etárias. Consideraram-se crianças os indivíduos que possuíam entre zero e 
doze anos de idade incompletos e como adolescentes aqueles entre 12 e 18 anos de idade incompletos, de acordo com o Estatuto da Criança e do Adolescente (ECA) (Sabatovski e Fontoura, 2010); foram considerados jovens os indivíduos na faixa etária de 18 a 29 anos de idade incompletos, de acordo com o Estatuto da Juventude do Rio de Janeiro ${ }^{3}$; foram classificados como idosos os indivíduos que possuíam mais de 60 anos, de acordo com o Estatuto do Idoso (Ramayana, 2004). Desta forma, foram considerados adultos os indivíduos que estavam com idade entre a faixa etária de jovem e idoso, compreendida entre 29 e 60 anos de idade incompletos.

O projeto deste estudo foi aprovado pelo Comitê de Ética em Pesquisa com Seres Humanos da Universidade Federal do Tocantins, protocolo nํㅜ 048/2009.

\section{Resultados e discussão}

No Brasil, a anemia falciforme apresenta distribuição heterogênea, porém é mais predominante onde a proporção de afrodescendentes é maior. Sendo assim, a maior frequência da Hb S é observada nas regiões Norte e Nordeste, que sofreram grande influência da raça negra na constituição étnica da população (Zago, 2002; Ducatti e col., 2001).

Neste estudo foram analisadas 167 amostras de sangue, sendo 48 provenientes da comunidade Malhadinha, 55 da comunidade Córrego Fundo, 27 da comunidade Curralinho do Pontal e 38 da comunidade Manoel João. Do total analisado, 156 indivíduos $(93,4 \%)$ apresentaram perfil eletroforético normal (Hb AA) e $11(6,6 \%)$ a presença de hemoglobinas variantes. Dentre os resultados alterados, oito $(4,8 \%)$ foram diagnosticados como traço falciforme (Hb AS) e três $(1,8 \%)$ como hemoglobina C (Hb AC) (Tabela 1). Os dados das comunidades quilombolas neste estudo apresentaram proporção de 1 caso de $\mathrm{Hb}$ AS para cada 21 indivíduos estudados (1:21).

A prevalência do traço falciforme nas comunidades quilombolas foi a mesma encontrada nas pessoas de cor negra em um estudo realizado com dezesseis Estados brasileiros (Naoum, 200ob). No Estado do Tocantins, o trabalho intitulado Prevalência de Hemoglobinopatias em Brejinho de Nazaré apresentou um estudo com 802 amostras de sangue provenientes de alunos, funcionários e professores de duas escolas públicas do município. Os indivíduos em estudo foram diferenciados em duas populações: brancos e negros. 0 resultado encontrado dentro da população negra foi o que mais predominou $(89,4 \%)$, onde $6,1 \%$ dos indivíduos manifestaram hemoglobinopatias, sendo mais frequente a $\mathrm{Hb}$ AS ( $4 \%$ ), seguida da Hb AC (2,1\%). O estudo expandiu-se para as famílias dos indivíduos que apresentaram algum tipo de anemia hereditária, resultando num total de 198 indivíduos. Esta amostragem revelou a incidência de $1,5 \%$ das pessoas com $\mathrm{Hb}$ SS e $20,7 \%$ Hb AS (Oliveira, 1997).

A prevalência de $\mathrm{Hb}$ AS nas comunidades quilombolas apresentou variação de o\% na Comunidade Manoel João até 12,5\% na comunidade Malhadinha (Tabela 1). Esse resultado mostra que a incidência do alelo S pode variar dentro da mesma região. Apesar das comunidades quilombolas serem constituídas por afrodescendentes, elas podem diferenciar nas suas histórias de origem.

Pedrosa e colaboradores (2004) realizaram um levantamento da distribuição da Hb S em 24 áreas remanescentes de quilombos, presentes nas diferentes unidades federativas do Brasil. Esses pesquisadores obtiveram, em três comunidades quilombolas, resultados semelhantes aos encontrados nas comunidades Manoel João e Malhadinha. Nas comunidades Itamoari (no Pará) e Paredão (Rio Grande do Sul), não foram encontrados portadores do alelo S, enquanto que na comunidade Riacho de Sacutiaba (Bahia) $13 \%$ da população amostrada apresentou $\mathrm{Hb}$ AS. Ao analisar todas as 24 áreas remanescentes de quilombos, a frequência da $\mathrm{Hb}$ AS foi de 3,7\%, semelhante ao encontrado nas comunidades quilombolas de Brejinho de Nazaré.

$\mathrm{Na}$ comunidade Malhadinha, a prevalência de $\mathrm{Hb}$ AS (Tabela 1) foi considerada alta quando comparada com a estimada entre afrodescendentes da região norte do Brasil (6 a 10\%) (Cançado e Jesus, 2007). Contudo, encontra-se dentro da média obtida para alguns países do continente africano. Em Gana a incidência de Hb AS varia de 10 a 22\% e em Angola entre 11 e 37\%. A semelhança dos resultados entre

3 Projeto de lei no 227/2007. Dispõe sobre o Estatuto da Juventude no Âmbito do Estado do Rio de Janeiro e dá outras providências. Assembleia Legislativa do Estado do Rio de Janeiro, 2007. 
o Continente Africano e o Brasil pode ser explicada pela origem da população negra brasileira. Estudos realizados através da análise do DNA mitocondrial dos indivíduos com doença falciforme mostraram que a maioria dos negros no Brasil é originária de regiões da África Central, como Angola, Gana, Benin e Togo (Brasil, 2009; Naoum, 2011).

O estudo das hemoglobinas evidenciou a incidência de $2 \%$ dos indivíduos com $\mathrm{Hb}$ AS na comunidade Córrego Fundo e $4 \%$ em Curralinho do Pontal. Na comunidade Córrego Fundo, também foram detectados portadores de $\mathrm{Hb} \mathrm{AC} \mathrm{(5 \% )} \mathrm{(Tabela} \mathrm{1).}$

\section{Tabela I - Número e proporção (\%) de entrevistados segundo diferentes tipos de hemoglobinas nas comunidades quilombolas Malhadinha, Córrego Fundo, Curralinho do Pontal e Manoel João, 2011}

\begin{tabular}{|c|c|c|c|c|}
\hline \multirow{2}{*}{ Local } & \multicolumn{3}{|c|}{ Tipos de hemoglobinas } & \multirow{2}{*}{ Total } \\
\hline & $\mathrm{Hb}$ AA & $\mathrm{Hb}$ AS & $\mathrm{Hb} \mathrm{AC}$ & \\
\hline \multirow[t]{2}{*}{ Córrego Fundo } & 51 & 1 & 3 & 55 \\
\hline & $(93,0 \%)$ & $(2,0 \%)$ & $(5,0 \%)$ & $(100 \%)$ \\
\hline \multirow[t]{2}{*}{ Curralinho do Pontal } & 25 & I & - & 26 \\
\hline & $(96,0 \%)$ & $(4,0 \%)$ & $(-)$ & (100\%) \\
\hline \multirow[t]{2}{*}{ Malhadinha } & 42 & 6 & - & 48 \\
\hline & $(87,5 \%)$ & $(12,5 \%)$ & $(-)$ & (100\%) \\
\hline \multirow[t]{2}{*}{ Manoel João } & 38 & - & - & 38 \\
\hline & （100\%） & $(-\%)$ & $(-)$ & (100\%) \\
\hline \multirow[t]{2}{*}{ Total } & 156 & 8 & 3 & 167 \\
\hline & $(93,4 \%)$ & $(4,8 \%)$ & $(1,8 \%)$ & $(100 \%)$ \\
\hline
\end{tabular}

A incidência de $\mathrm{Hb} \mathrm{AC}$ ( $5 \%$ ) encontrada na comunidade Córrego Fundo foi predominante à da $\mathrm{Hb} \mathrm{AS}$ ( $2 \%)$. A alta prevalência de $\mathrm{Hb}$ AC pode ser justificada ao levar em consideração a população étnica investigada (descendentes de negros e escravos). Esse resultado é compatível ao relato de Naoum (1984), onde afirma que a $\mathrm{Hb}$ AC é característica dos povos africanos, sendo encontrada com frequência de 5 e $25 \%$ da população, em muitas regiões da África.

Desse modo, dentre as amostras analisadas nas comunidades quilombolas, foram identificadas a presença de $\mathrm{Hb} \mathrm{S} \mathrm{e} \mathrm{C,} \mathrm{entretanto,} \mathrm{todas} \mathrm{elas} \mathrm{apresen-}$ taram-se em heterozigose. Embora nenhum indivíduo com anemia falciforme tenha sido amostrado, estima-se o nascimento de futuros homozigotos (Hb SS) ou dupla heterozigose (Hb SC) na população investigada, provenientes da união de portadores de $\mathrm{Hb}$ AS e $\mathrm{Hb}$ AC.

A variabilidade clínica da anemia falciforme está associada aos diferentes tipos de haplótipos, níveis de $\mathrm{Hb}$ Fetal e interações com talassemia alfa que atuam como modeladores genéticos da doença. Além desses fatores caracterizados como interferentes eritrocitários, o doente fica vulnerável aos interferentes do meio ambiente no qual está inserido. Entre eles destacam-se as situações sociais, econômicas e culturais do indivíduo (Naoum, 200oa).

Portanto, apesar de não ter sido detectado nenhum indivíduo com anemia neste estudo, a condição social, econômica, política e cultural das famílias das comunidades quilombolas também refletem diretamente nas condições de saúde desta população e podem ser fatores determinantes para o aumento do número de doente falciforme.

$\mathrm{Na}$ avaliação do perfil socioeconômico, foram estudadas cerca de 12 famílias em cada comunidade quilombola, resultando em 208 indivíduos amostrados, sendo 91 (43,75\%) do sexo feminino e 117 $(56,25 \%)$ do sexo masculino.

O número de indivíduos avaliados na caracterização do perfil social das comunidades foi maior que o número de indivíduos amostrados para a triagem 
das hemoglobinas. Essa diferença se deve ao fato de muitos familiares não estarem em casa no momento da pesquisa, não sendo possível coletar o seu material biológico. Porém, no momento da entrevista foram registrados os dados de todos os moradores da residência, mesmo dos ausentes, a maioria deles estava no trabalho ou na escola.

O estudo da faixa etária indicou que as comunidades quilombolas do município de Brejinho de Nazaré são formadas predominantemente por adultos e idosos, que juntos compõem, 5o, 56, 6o e 63\% das comunidades de Malhadinha, Córrego Fundo, Curralinho do Pontal e Manoel João, respectivamente (Tabela 2). De modo geral, essas comunidades apresentaram um percentual maior de crianças $(19,2 \%)$ do que de jovens $(15,4 \%)$ e adolescentes (9,1\%), sendo que 19 dessas crianças moram com os pais e avós. Segundo Fiabani (2011), é comum observar o círculo familiar de muitas comunidades quilombolas ampliado pela inserção de netos e sobrinhos.

A baixa concentração de jovens e adolescentes nas comunidades pode ser explicada pela necessidade de eles se dirigirem às cidades vizinhas para estudar e trabalhar (Brejinho de Nazaré, Porto Nacional, Gurupi ou Ipueiras). Contudo, mesmo não estando na comunidade, esses jovens necessitam de atenção especial, pois se trata de um grupo em fase reprodutiva, que na grande maioria desconhece o perfil de suas hemoglobinas. Considerando o fato de que há casamentos entre indivíduos das comunidades quilombolas, os que apresentam traço falciforme ou hemoglobina $\mathrm{C}$ devem ter a informação quanto ao seu genótipo, pois isso poderá reduzir o nascimento de crianças com anemia hemolítica.

O estudo dos aspectos econômicos das quatro comunidades quilombolas de Brejinho de Nazaré demonstrou que 50,0\% das famílias apresentaram renda familiar mensal maior que um salário mínimo (Tabela 3). Essa alta percentagem se deve ao grande número de indivíduos aposentados; a maioria recebe o benefício pela idade, no entanto 6,o\% das aposentadorias são destinadas às pessoas com deficiência física ou mental, podendo haver mais de uma pessoa recebendo o benefício na mesma família.

A renda nas comunidades se deve, principalmente, à aposentadoria, à agricultura de subsistência, trabalhos informais praticados pelos adultos e ao recebimento de benefício proveniente do programa Bolsa Família. Ele visa promover o alívio imediato das famílias que se encontram em situação de pobreza, através da transferência direta de renda (Oliveira e col., 2007). No entanto, essa renda ainda é insuficiente para a manutenção das famílias, principalmente para aquelas com pessoas idosas e ou deficientes, que precisam de tratamento especializado.

Apesar de o portador do traço falciforme ou da hemoglobina C (na forma heterozigota) não possuírem alterações clínicas que necessitem de

\section{Tabela 2 - Número e proporção (\%) de moradores segundo faixa etária nas comunidades quilombolas de Córrego Fundo, Curralinho do Pontal, Malhadinha e Manoel João, 20II}

\begin{tabular}{lcccccc} 
& \multicolumn{2}{c}{ Faixa etária das comunidades } & & Total \\
Local & Criança & Adolescente & Jovem & Adulto & Idoso & 63 \\
Córrego Fundo & 13 & 8 & 7 & 26 & 9 & $(41,3 \%)$ \\
Curralinho do Pontal & $(20,6 \%)$ & $(12,7 \%)$ & $(11,1 \%)$ & $(14,3 \%)$ & $(100 \%)$ \\
& 2 & 5 & 9 & 13 & 11 & 40 \\
Malhadinha & $(5,0 \%)$ & $(12,5 \%)$ & $(22,5 \%)$ & $(32,5 \%)$ & $(27,5 \%)$ & $(100 \%)$ \\
& 16 & 4 & 11 & 23 & 8 & 62 \\
Manoel João & $(25,8 \%)$ & $(6,5 \%)$ & $(17,7 \%)$ & $(37,1 \%)$ & $(12,9 \%)$ & $(100 \%)$ \\
& 9 & 2 & 5 & 18 & 9 & 43 \\
Total & $(20,9)$ & $(4,7)$ & $(11,6)$ & $(41,9)$ & $(20,9)$ & $(100)$ \\
& 40 & 19 & 32 & 80 & 37 & 208 \\
& $(19,2 \%)$ & $(9,1 \%)$ & $(15,4 \%)$ & $(38,5 \%)$ & $(17,8 \%)$ & $(100 \%)$ \\
\hline
\end{tabular}


Tabela 3 - Número e proporção (\%) de famílias segundo renda salarial das comunidades quilombolas de Córrego Fundo, Curralinho do Pontal, Malhadinha e Manoel João, 20II

\begin{tabular}{lcccc} 
Local & \multicolumn{3}{c}{ Renda em Salários Mínimos* } & Total \\
Córrego Fundo & $<$ I SM & $=$ । SM & $>$ I SM & 12 \\
& 3 & 3 & 6 & $(100 \%)$ \\
Curralinho do Pontal & $(25,0 \%)$ & $(25,0 \%)$ & $(50,0 \%)$ & 11 \\
& 2 & 0 & $(81,8 \%)$ & $(100 \%)$ \\
Malhadinha & $(18,2 \%)$ & $(0,0 \%)$ & 3 & 12 \\
& 3 & 6 & $(25,0 \%)$ & $(100 \%)$ \\
Manoel João & $(25,0 \%)$ & $(50,0 \%)$ & 6 & 13 \\
& 3 & 4 & $(46,2 \%)$ & $(100 \%)$ \\
Total & $(23,1 \%)$ & $(30,8 \%)$ & 24 & 48 \\
& 11 & 13 & $(50,0 \%)$ & $(100 \%)$ \\
\hline
\end{tabular}

*(< । SM - menor que । salário mínimo; = ISM - igual a । salário mínimo; > I SM = maior que । salário mínimo)

acompanhamento médico, a restrição de recurso financeiro limita o acesso ao diagnóstico. Esse fato foi observado na comunidade Malhadinha, onde alguns moradores relataram conhecer os agravos da anemia falciforme por haver caso da doença na família. Mesmo assim, somente os parentes mais próximos do doente (já falecido) haviam realizado exames para o diagnóstico das suas hemoglobinas. A ausência do diagnóstico dos outros familiares foi justificada pela falta de recurso para custear os exames.

A condição econômica é um importante interferente social que influencia diretamente a vida das famílias quilombolas. Muitas vezes, por não terem renda familiar satisfatória, as famílias não possuem uma alimentação adequada, resultando em deficiência alimentar e baixa qualidade nutricional, o que pode agravar sua condição de saúde. A falta de recurso também limita o acesso à informação (Fundação Cultural Palmares e Fundação Universidade de Brasília, 2004; Freitas e col., 2011).

Outro ponto bastante relevante está relacionado com as informações sobre a anemia e traço falciforme disponibilizadas para os integrantes das comunidades quilombolas. Segundo Assis (2010), é importante que sejam realizadas estratégias de educação em saúde nas comunidades, relacionando informações pertinentes, como as discutidas no pre- sente trabalho. Tais informações poderiam ser vinculadas nas escolas frequentadas pelos estudantes da comunidade, repassadas pelos agentes de saúde, ou até mesmo através de veículos de informações, como o rádio e a televisão.

Para exemplificar a necessidade da divulgação de informações sobre a doença, relata-se a abordagem realizada pela equipe em uma família da comunidade Malhadinha na qual a mãe não se interessou em participar do trabalho porque o filho dizia-se cansado de realizar exames cardíacos e frequente coleta de sangue. Ambos mostraram-se desconhecedores dos agravos das anemias hemolíticas, apesar de o menino apresentar as características físicas observadas no indivíduo com anemia falciforme.

Os aspectos ambientais dos locais de moradia das comunidades também podem interferir na qualidade da saúde e se caracterizam pela inexistência de saneamento básico, qualidade inadequada de higiene e ausência de tratamento da água. Outro fator importante está relacionado com a deficiência na assistência médica, social e psicológica, pois as comunidades não possuem posto de saúde e por esse motivo as famílias precisam procurar atendimento nas cidades vizinhas, porém esse acesso é dificultado pela ausência de transporte (Silva, 2007; Freitas e col., 2011). Este quadro também foi encontrado nas comunidades quilombolas de Brejinho de Nazaré, 
onde a ausência de postos de saúde prejudica o diagnóstico das hemoglobinopatias e de outras doenças que acometem a população, além de comprometer o tratamento de suas enfermidades.

Com as restrições encontradas no ambiente rural, algumas famílias quilombolas optam por migrar para a cidade, em busca de melhorias na educação, saúde e renda familiar. Isso desencadeia outros problemas sociais, dentre eles, a perda da sua identidade cultural (Pinheiro e col., 2013). Desse modo, é visível a necessidade de serviços que possam melhorar a qualidade de vida nas comunidades quilombolas. Na pesquisa de campo, observou-se que os serviços mais urgentes são: atendimento médico, implantação de saneamento básico, construção de escolas, transporte, desenvolvimento de projetos para melhorar as formas de geração de renda e a disseminação de informações pertinentes aos cuidados com a saúde da população.

\section{Considerações finais}

As comunidades quilombolas eram regiões bastante desconhecidas no cenário das pesquisas sobre distribuição da hemoglobina $\mathrm{S}$ e esta pesquisa buscou atenuar a lacuna presente na literatura. Foi observado que o número de casos referentes aos heterozigotos para hemoglobina S e C apresentou-se elevado, representando o risco para o aumento da incidência da doença no Estado do Tocantins. A falta de informação/conhecimento sobre o assunto pode levar os casais com traços falciformes ou $\mathrm{Hb} \mathrm{C}$ a terem filhos com anemia hemolítica grave, sendo necessária uma divulgação mais intensa sobre a anemia falciforme e outras hemoglobinopatias que possam acometer a população tocantinsense.

Além disso, o diagnóstico de doenças genéticas, como a anemia falciforme, nas comunidades quilombolas é comprometido pela falta de estrutura no atendimento à saúde e pela baixa renda da população, que não dispõe de recurso para custear os exames.

Diante do exposto, fica evidente a necessidade de continuar investigando as hemoglobinas variantes na população tocantinense, e da ação do Programa Nacional de Triagem Neonatal para as hemoglobinopatias, que proporciona o diagnóstico precoce para o recém- -nascido. O diagnóstico precoce representa grande importância no âmbito da saúde pública, pois reduz a mortalidade infantil e as necessidades de internações. Portanto, atenção especial deve ser dada à saúde da população negra, principalmente em comunidades quilombolas, que apresenta baixa condição financeira e difícil acesso aos serviços de saúde.

\section{Agradecimentos}

Agradecemos às comunidades quilombolas Córrego Fundo, Curralinho do Pontal, Malhadinha e Manoel João, por receberem a equipe.

\section{Referências}

ASSIS, E. S. Estudo das síndromes falcêmicas em comunidade quilombola, Sergipe / Brasil. 2010. Dissertação (Mestrado em Saúde e Ambiente) Universidade Tiradentes, Aracajú, 2010.

BALLAS, S. K.; MOHANDAS, N. Pathophisiology of vaso-occlusion. Hematology/Oncology Clinics of North America, Philadelphia, v. 10, n. 6, p. 1221$1240,1996$.

BEZERRA, M. A. C. et al. Molecular variations linked to the grouping of $\beta$ and $\alpha$-globin genes in neonatal patients with sickle cell disease in the state of Pernambuco, Brazil. Hemoglobin, New York, v. 31, n. 1, p. 83-88, 2007.

BONINI-DOMINGOS, C. R. Metodologias

laboratoriais para o diagnóstico de

hemoglobinopatias e talassemias. São José do Rio Preto: HN, 2006.

BONINI-DOMINGOS, C. R. As hemoglobinopatias e a diversidade genética da população brasileira.

Revista Brasileira de Hematologia e Hemoterapia, São José do Rio Preto, v. 31, n. 6, p. 401, 2009.

BONINI-DOMINGOS, C. R. et al. Interação entre Hb C [beta6(А3) Glu>Lys] e IVS II-654 (C>T) beta-talassemia no Brasil. Revista Brasileira de Hematologia e Hemoterapia, São José do Rio Preto, v. 25, n. 2, p. 115-121, 2003.

BRASIL. Ministério da Saúde. Secretaria de Atenção à Saúde. Departamento de Atenção Especializada. Manual da anemia falciforme para a população. Brasília, DF, 2007. 
BRASIL. Ministério da Saúde. Secretaria de Atenção à Saúde. Departamento de Atenção Especializada. Manual de educação em saúde: linha de cuidado em doença falciforme. Brasília, DF, 2009.

CANÇADO, R. D.; JESUS, J. A.A doença falciforme no Brasil. Revista Brasileira de Hematologia e Hemoterapia, São José do Rio Preto, v. 29, n. 3, p. 203-206, 2007.

DI NUZZO, D. V. P.; FONSECA, S. F. Anemia falciforme e infecções. Jornal de Pediatria, Rio de Janeiro, v. 8o, n. 5, p.347-354, 2004.

DUCATTI, R. P. et al. Investigação de hemoglobinopatias em sangue de cordão umbilical de recém-nascidos do Hospital de Base de São José do Rio Preto. Revista Brasileira de Hematologia e Hemoterapia, São José do Rio Preto, v. 23, n. 1, p. 23-29, 2001.

FIABANI, A. As terras dos quilombolas. In: LOPES, M. A. O. Entre o costume e a lei: superando o "silêncio" e descortinando a história afrobrasileira. São José: Premier, 2011. p.155 - 184.

FREITAS, D. A. et al. Saúde e comunidades quilombolas: uma revisão da literatura. Revista CEFAC, São Paulo, v. 13, n. 5, p. 937-943, 2011.

FUNDAÇÃO CULTURAL PALMARES. Comunidades quilombolas. Brasília, 2013. Disponível em: <http://www.palmares.gov.br/?page $\mathrm{id}=88 \&$ estado=TO $>$. Acesso em: 9 jun. 2013.

FUNDAÇÃO CULTURAL PALMARES; FUNDAÇÃO UNIVERSIDADE DE BRASÍLIA. Diagnóstico sócio-econômico-cultural das comunidades remanescentes de quilombos: relatório geral. Brasília, DF, 2004. Disponível em: <www.ambiente. sp.gov.br/wp-content/uploads/cea/diagnostico. pdf $>$. Acesso em: 9 jun. 2013.

GALIZA-NETO, G. C. et al. Analysis of $\beta$ S globin gene haplotypes in Ceará, Brazil. Jornal Brasileiro de Patologia e Medicina Laboratorial, Rio de Janeiro, v. 41, n. 5, p. 315-321, 2005.
GONÇALVES, M. S. et al. Beta S-Haplotypes in sickle cell anemia patients from Salvador, Bahia, Northeastern Brazil. Brazilian Journal of Medical and Biological Research, Ribeirão Preto, v. 36, n. 10, p. 1283-1288, 2003.

HARKNESS, D. R. Sickle cell trait revisited. The American Journal of Medicine, New York, v. 87, n. 3, p. 30-34, 1989.

IBGE - INSTITUTO BRASILEIRO DE GEOGRAFIA E ESTATÍSTICA. Resultados preliminares do universo do Censo Demográfico 2010. Rio de Janeiro, 2011. Disponível em: <http://www.ibge.gov. $\mathrm{br} / \mathrm{estadosat} /$ temas.php? sigla=to\&tema=resultprel univer_censo2010 >. Acesso em: 30 out. 2011.

JOISHY, S. K. et al. Clinical, genetic and fertility studies of Indian with s-globin gene and the influence of $\mathrm{Hb} \mathrm{S}$ on Plasmodium falciparum malaria infection. Transactions of the Royal Society of Tropical Medicine and Hygiene, London, v. 82, n.4, p. 515-519, 1988.

KREUELS, B. et al. Differing effects of $\mathrm{HbS}$ and $\mathrm{HbC}$ traits on uncomplicated falciparum malaria, anemia, and child growth. Blood, Washington, DC, v. 15, n. 2, p. 4551-4558, 2010.

MODIANO, D. et al. Hemoglobin C protects against clinical Plasmodium falciparum malária. Nature, London, v. 414, n. 6861, p. 305-308, 2001.

MURAO, M.; FERRAZ, M. H. Traço falciforme heterozigose para hemoglobinopatias. Revista Brasileira de Hematologia e Hemoterapia, São José do Rio Preto, v. 29, n. 3, p. 223-225, 2007.

NAOUM, P. C. Anemias imigrantes: origem das anemias hereditárias no Brasil. Revista Ciência Hoje, São Paulo, v. 3, n. 14, p. 58-64, 1984.

NAOUM, P. C. Interferentes eritrocitários e ambientais na anemia falciforme. Revista Brasileira de Hematologia e Hemoterapia, São José do Rio Preto, v. 22, n. 1, p. 5-22, 2000 .

NAOUM, P. C. Prevalência e controle da hemoglobina S. Revista Brasileira de Hematologia e Hemoterapia, São José do Rio Preto, v. 22, n. 2, p. 142-148, 200ob. 
NAOUM, P. C. Sickle cell disease: from the beginning until it was recognized as a public health disease. Revista Brasileira de Hematologia e Hemoterapia, São José do Rio Preto, v. 33, n. 1, p. 7-9, 2011.

NASCIMENTO, J. B. Tocantins: história e geografia. Goiânia: Bandeirante, 2009.

OLIVEIRA, A. M. H. C. et al. Primeiros resultados da análise da linha de base da pesquisa de avaliação de impacto do Programa Bolsa Família. In: BRASIL. Ministério do Desenvolvimento Social e Combate à Fome. Avaliação de políticas e programas do MDS: resultados. Brasília, DF, 2007.p. 19-66.

OLIVEIRA, J. S. Prevalência de hemoglobinopatias em Brejinho de Nazaré-Tocantins. 1997.

Monografia (Bacharelado em Ciências Biológicas) - Fundação Universidade Federal do Tocantins, Porto Nacional, 1997.

PASCAL, R. etal. Hemoglobin C is associated with reduced Plasmodium falciparum parasitemia and low risk of mild malaria attack. Human Molecular Genetics, New York, v. 13, n. 1, p. 1-6, 2004.

PEDROSA, M. A. F.; FERREIRA, L. B.; OLIVEIRA, S. F. Anemia falciforme em antigos quilombos. Ciência Hoje, São Paulo, v. 36, n. 211, p. 84-85, 2004

PINHEIRO, E. P. et al. Quilombolas no centro urbano de Monte do Carmo -TO. Revista Interface, Porto Nacional, n. 6, p. 32-39, maio 2013. Disponível em: <http://www.uft.edu.br/revista/ index.php/interface/article/view/482/304>. Acesso em: 9 jul. 2013.
PINTO, E. A.; LUPINACCI, F. L.; SANTOS, G. E. R. (Org.). Doenças falciformes: programa de atenção integral às pessoas com doenças falciformes e outras hemoglobinopatias da cidade de São Paulo. São Paulo: Codepps, 2008. Disponível em: <http://ww2.prefeitura.sp.gov.br/arquivos/ secretarias/saude/popnegra/DoencaFalciforme_ ProgramaAtencaoIntegral.pdf $>$. Acesso em: 3 jun. 2013.

RAMAYANA. M. Estatuto do idoso comentado. Rio de Janeiro: Roma Victor,2004.

RIEDER, R. F. et al. Effect of beta-globin gene cluster haplotype on the hematological and clinical features of sickle cell anemia. American Journal of Hematology, New York, v. 36, n. 3, p. 184-189, 1991.

SABATOVSKI, E.; FONTOURA, I. P. Estatuto da Criança e do Adolescente: ECA . Curitiba: Jurua, 2010.

SILVA, J. A. N. Condições sanitárias e de saúde em Caiana dos Crioulos, uma comunidade quilombola do estado da Paraíba. Saúde e Sociedade, São Paulo, v. 16, n. 2, p. 111-124, 2007.

VICENTINO, C.; DORIGO, G. História geral e do Brasil. São Paulo: Scipione, 2002.

ZAGO, M. A. Considerações gerais. In: ANVISA - AGÊNCIA NACIONAL DE VIGILÂNCIA SANITÁRIA. Manual de diagnóstico e tratamento de doenças falciformes. Brasília, DF, 2002. p. 7-12.

ZAGO, M. A. et al. Bantu beta S cluster haplotype predominant among Brazilian blacks. American Journal of Physical Anthropology, Hoboken, v. 88, n. 3, p. 295-298, 1992.

Recebido em: 15/03/2012

Reapresentado em: II/07/2013

Aprovado em: 17/07/2013 